\title{
Novel Approaches to the Management of Graves' Ophthalmopathy
}

\author{
Luigi Bartalena ${ }^{1}$, Maria Laura Tanda ${ }^{1}$, Alessandra Medea ${ }^{1}$, Claudio Marcocci ${ }^{2}$, \\ Aldo Pinchera ${ }^{2}$
}

Departments of Endocrinology, ${ }^{1}$ University of Insubria, Varese,${ }^{2}$ University of Pisa, Pisa, Italy

\begin{abstract}
Severe Graves' ophthalmopathy constitutes a complex therapeutic challenge and treatment outcome often is not satisfactory. Established methods of treatment include high-dose glucocorticoids, orbital radiotherapy and orbital decompression. Recently, the use of intravenous glucocorticoids has been shown to provide more favorable results than oral glucocorticoids. Novel treatments under investigation include somatostatin analogues, intravenous immunoglobulins and antioxidants. Low-dose immunosuppressive drugs (namely cyclosporine and, possibly, methotrexate) might be useful as an adjunct to established methods, particularly in view of a glucocorticoid-sparing action. Because cytokines play an important role in the pathogenesis of the disease, cytokine antagonists, which are currently evaluated in rheumatoid arthritis and other autoimmune conditions, might constitute in the future a valuable tool for the management of eye disease. Prevention of Graves' ophthalmopathy would be desirable, but so far it is limited to secondary prevention (arrest of progression of subclinical disease to clinical disease) and tertiary prevention (avoidance of deterioration or complications of clinical disease): among preventive measures smoking withdrawal is probably the most important one. Primary prevention (in the absence of disease) is only speculative, but oral tolerance induction or vaccination with the offending antigen(s) might prove beneficial for prevention of Graves' ophthalmopathy in genetically susceptible individuals.
\end{abstract}

Key-Words: Graves' ophthalmopathy, cytokines, cytokine antagonists, somatostatin analogues, methotrexate, oral tolerance, pentoxifylline

\section{INTRODUCTION}

Graves' ophthalmopathy (GO) is the complex of ocular signs and symptoms often present in Graves' disease; similar eye involvement can, however, less frequent-

Address correspondence and requests for reprints to: Prof. Luigi Bartalena, University of Insubria, Ospedale di Circolo, Viale Borri, 57, 21100 Varese, Italy. Phone \& Fax: +39-0332-278561; e-mail: 1.bartalena@libero.it

Received 22-02-02, Accepted 10-03-02 ly be observed in patients with Hashimoto's thyroiditis or in subjects with no apparent thyroid abnormalities (socalled Euthyroid Graves' Disease $)^{1}$. In most cases, ocular involment is nonsevere, but $3-5 \%$ of cases have severe and progressive ocular manifestations ${ }^{1}$. It is noteworthy that the quality of life of affected individuals is markedly impaired not only in severe ophthalmopathy but also in nonsevere eye disease ${ }^{2}$.

Severe GO represents a complex therapeutic problem and, despite any effort, approximately one third of 
patients are dissatisfied with the therapeutic outcome at the end of follow-up ${ }^{3}$. This is because currently available methods of treatment frequently result in a partial or absent response of the ophthalmopathy. The unfavorable outcome can partly be explained by selection of patients because longstanding and inactive GO is unlikely to show relevant and substantial changes in response to whatever medical treatment, while results are more likely to be favorable in recent-onset and active eye disease ${ }^{1}$.

Available treatments for GO are listed in Table 1. They have recently been extensively reviewed ${ }^{1,4}$. The aim of the present article is to analyze novel treatments (or novel modalities of established treatments) currently under investigation as well as therapeutic and preventive perspectives for this disease.

\section{INTRAVENOUS GLUCOCORTICOIDS}

Glucocorticoids have been used for decades and still represent a milestone in GO management due to their nonspecific anti-inflammatory and immunosuppressive actions $^{4,5}$. In a recent survey of the European Thyroid Association they were indicated as the first-line treatment, alone or in combination with orbital radiotherapy, by the majority of respondents ${ }^{6}$. They have been administered via systemic (mainly oral until 15 years ago) or local (subconjunctival or retrobulbar) routes? ${ }^{7}$. Oral glucocorticoids provide overall favorable responses in slightly more than $60 \%$ of patients, whereas the local route is associated with beneficial effects only in about $40 \%$ of cases ${ }^{1}$. They are mostly effective in patients with severe and active florid eye disease. Soft tissue inflammatory changes, recent-onset extraocular muscle involvement, and optic neuropathy are the most responsive expressions of the disease, while proptosis and longstanding extraocular muscle involvement associated with fibrotic changes are poorly influenced by treatment. The major drawbacks of glucocorticoid treatment are the

Table 1. Methods of medical treatment for Graves' ophthalmopathy.

\begin{tabular}{|c|c|}
\hline & Comment \\
\hline \multicolumn{2}{|l|}{ High-dose glucocorticoids } \\
\hline Oral & Effective on severe and active GO \\
\hline Intravenous & Effective on severe and active GO; better tolerated than oral steroids \\
\hline Local & Low effectiveness \\
\hline \multicolumn{2}{|l|}{ Retrobulbar } \\
\hline \multicolumn{2}{|l|}{ Subconjunctival } \\
\hline Orbital radiotherapy & Effective on severe and active GO; more effective if associated with glucocorticoids \\
\hline Somatostatin analogues & Effective on severe and active GO; limited number of treated patients; high cost \\
\hline \multicolumn{2}{|l|}{ Octreotide } \\
\hline \multicolumn{2}{|l|}{ Lanreotide } \\
\hline Intravenous immunoglobulins & Limited number of treated patients; high cost; risks related to plasma-derived products \\
\hline \multicolumn{2}{|l|}{ Immunosuppressive drugs } \\
\hline Azathioprine & Poorly effective \\
\hline Cyclophosphamide & Poorly effective \\
\hline Chlorambucil & Poorly effective \\
\hline Ciamexone & Poorly effective \\
\hline Cyclosporine & $\begin{array}{l}\text { Limited effectiveness as a single-agent; possible use in association with glucocorticoids } \\
\text { (glucocorticoid-sparing effect) }\end{array}$ \\
\hline \multicolumn{2}{|l|}{ Antioxidants } \\
\hline Allopurinol and Nicotinamide & Only one pilot (nonrandomized) study \\
\hline \multicolumn{2}{|l|}{ Cytokine antagonists } \\
\hline IL-1 antagonists & $\begin{array}{l}\text { Studies in vitro for GO; used in vivo in other autoimmune disorders; } \\
\text { preliminary study on pentoxifylline }\end{array}$ \\
\hline TNF-a antagonists & Used in vivo in other autoimmune disorders; preliminary study on pentoxifylline \\
\hline Total thyroid ablation & Only few uncontrolled and nonrandomized studies of GO \\
\hline
\end{tabular}


need for continuative administration of high doses of the drug, the long duration of treatment, the frequent relapses of the ophthalmopathy after drug withdrawal and the frequent and potentially dangerous adverse effects and complications ${ }^{7}$.

Glucocorticoids do not constitute a novel treatment for GO. What is relatively new is the intravenous (iv) route of administration. Glucocorticoids, admistered as iv pulse therapy, repeated several times, have been used for the treatment of other autoimmune disorders, and have been employed for GO since 1987 (see 1 for review). An overall analysis of reported results indicates that favorable responses can be achieved in slightly less than $80 \%$ of cases ${ }^{1}$. However, interpretation of results is complicated by the lack of control groups (namely, oral glucocorticoids), by the heterogeneity of doses and protocols and by the virtually constant administration of oral glucocorticoids or immunosuppressive agents in the interpulse period ${ }^{(1}$. We recently reported the results of the first randomized prospective study directly comparing the effects of oral and iv glucocorticoids ${ }^{8}$. Patients were treated by orbital radiotherapy combined with either oral prednisone $(100 \mathrm{mg} /$ day, initial dose, to be gradually tapered and withdrawn over a 5 -month period) or iv methylprednisolone $(15 \mathrm{mg} / \mathrm{kg}$ bodyweight for $4 \mathrm{cy}-$ cles followed by $7.5 \mathrm{mg} / \mathrm{kg}$ bodyweight for 4 cycles; each cycle consisting of two infusions on alternate days at 2week intervals). No maintenance oral glucocorticoid treatment was given in the interpulse period. Each group included 41 patients whose baseline clinical and laboratory features did not differ. Both treatment modalities were effective, but the proportion of favorable responses was higher in the iv group ( $88 \%$ vs $63 \%$ in the oral group, $\mathrm{p}<0.005)^{8}$. Likewise, both treatments were associated with a significant reduction in the Clinical Activity Score (CAS), but CAS decrease after treatment was greater with the iv route $(\mathrm{p}<0.005 \text {; Figure } 1)^{8}$. This study also showed that the iv route was better tolerated than the oral route because side effects occurred in $56 \%$ of iv-treated patients and $83 \%$ of orally-treated patients (Table 2). In particular, cushingoid features, present in the large majority of orally-treated patients, were apparent in only a few patients treated by iv glucocorticoids (Table 2). It must be mentioned that one case of fatal acute liver failure was reported in a patient given high doses of iv glucocorticoids for $\mathrm{GO}^{9}$. We have observed a few cases of liver toxicity when the cumulative dose of steroids was higher than 10 grams; accordingly, we now use a lower cumulative dose of iv methylprednisolone (8 grams rather than 12-14 grams) and are satisfied with the lower liver toxicity of this regimen.

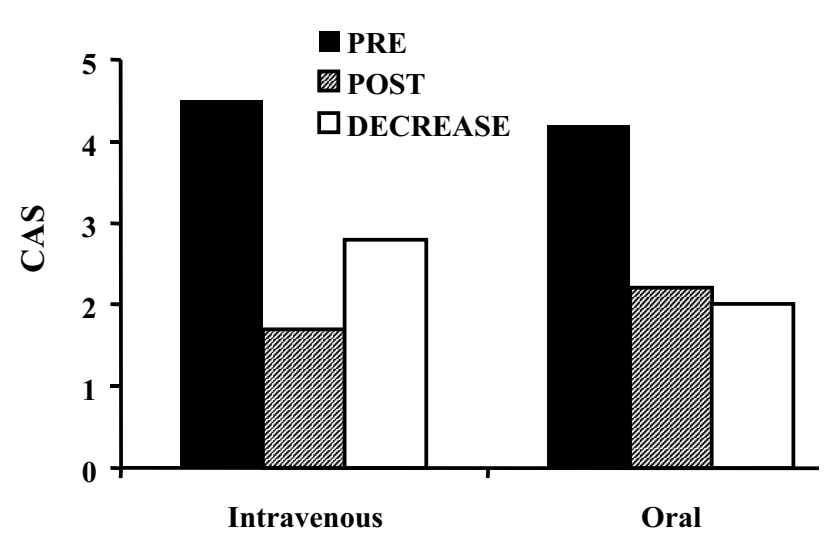

Figure 1. Changes in the Clinical Activity Score (CAS) following treatment of severe Graves' ophthalmopathy with either intravenous or oral high-dose glucocorticoids. Derived from Marcocci C et al. ${ }^{8}$.

Table 2. Side effects of intravenous and oral glucocorticoids in 82 patients with severe Graves' ophthalmopathy.

\begin{tabular}{|c|c|c|}
\hline & $\begin{array}{c}\text { Intravenous } \\
\mathrm{n}=41\end{array}$ & $\begin{array}{c}\text { Oral } \\
n=41\end{array}$ \\
\hline Gastritis & $4(10 \%)$ & $4(10 \%)$ \\
\hline Urinary tract infections & $8 \quad(20 \%)$ & $8 \quad(20 \%)$ \\
\hline Depression & $1(2.5 \%)$ & $2 \quad(5 \%)$ \\
\hline Hepatitis & $1(2.5 \%)$ & 0 \\
\hline Glucose intolerance & $9 \quad(22 \%)$ & $8 \quad(21 \%)$ \\
\hline Blood hypertension & $1(2.5 \%)$ & $(5 \%)$ \\
\hline Cushingoid features & $5(12 \%)$ & $35(85 \%)$ \\
\hline Total side effects* & 23 & 60 \\
\hline
\end{tabular}

*Some patients had more than one side effect or complication. Derived from Marcocci $\mathrm{C}$ et $\mathrm{al} .{ }^{8}$.

In summary, high-dose iv glucocorticoids appear to be more effective and better tolerated than oral glucocorticoids or locally-administered glucocorticoids (Figure 2). The rapidity of action of iv glucocorticoids make them a valuable and suitable treatment for very severe and active ophthalmopathy (so-called "malignant exophthalmos"), when an immediate surgical approach (orbital decompression) is generally advised: in these cases, a short-term (2-3 weeks) course of iv glucocorticoids can be carried out. In the absence of relevant beneficial effects, the patient will be submitted to surgery, but, if a response does occur (and this often is dramatic), medical treatment with iv steroids (possibly associated with orbital radiotherapy) can be continued.

\section{SOMATOSTATIN ANALOGUES}

The idea to use somatostatin analogues (SMSa) (oc- 


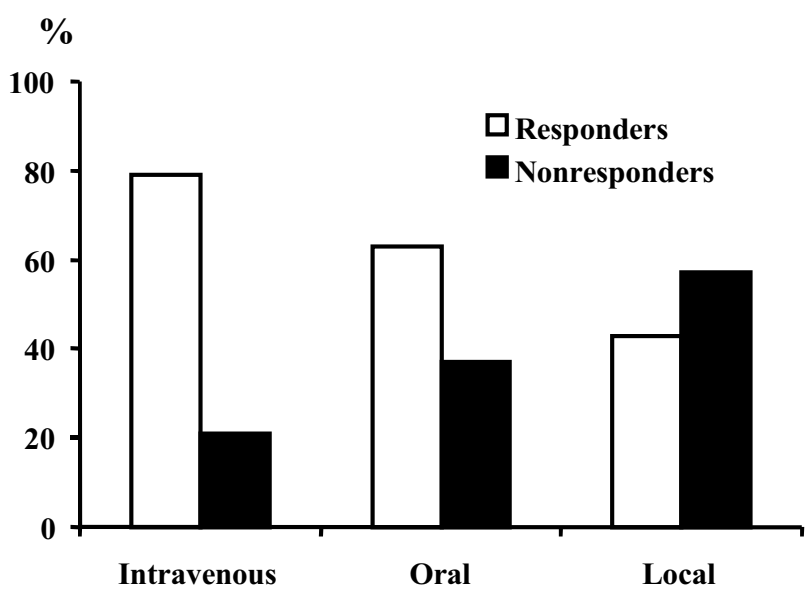

Figure 2. Overall effects of intravenous, oral or locally-administered glucocorticoids. Compiled from the literature.

treotide and lanreotide) for the management of severe and active GO derives from the observation that SMS receptors can be visualized in vivo in the orbital tissue of GO patients by ${ }^{111}$ In-DTPA-D-Phe-octreotide scintigraphy (octreoscan) ${ }^{10}$. Octreoscan positivity is higher in Graves' patients with than in those without ophthalmopathy ${ }^{11}$; in patients with active than in those with inactive $\mathrm{GO}^{11-13}$; in patients with recent-onset than in those with longstanding eye disease ${ }^{12}$. Octreoscan positivity correlates with other indicators of activity of the ophthalmopathy, such as high $\mathrm{CAS}^{10}$ or T2-relaxation time of the extraocular muscles at magnetic resonance imaging ${ }^{14}$. Thus, a positive octreoscan is an indicator of GO activity ${ }^{15}$ and may predict a subsequent favorable response not only to SMSa therapy but also to high-dose glucocorticoids and/or orbital radiotherapy ${ }^{11,16-18}$. Limitations to a wide-scale use of octreoscan in making a therapeutic decision for GO patients include: high demand of this technique in terms of accuracy needed for prediction, high cost, a not negligible radiation burden and relative lack of specificity (i.e., the number of false positives in other inflammatory or noninflammatory orbital disorders) ${ }^{15}$.

With this background, it is not surprising that several, although small, studies have investigated the effects of SMSa on GO (see refs. 5 and 19 for review). The mechanism of action of these drugs remains to be fully elucidated, but they might exert beneficial effects by modulating the immunologic and metabolic activities of orbital cells (fibroblasts, adipocytes, myocytes), which contribute to perpetuation of immune and inflammatory reactions ongoing in the orbit of affected individuals ${ }^{5}$. The use of SMSa in GO patients was first reported by
Chang et al. ${ }^{20}$ in an uncontrolled study of 6 patients treated with $0.1 \mathrm{mg}$ subcutaneous octreotide three times daily for 3 months: treatment was associated with an improvement in soft tissue inflammatory changes and extraocular muscle impairment. In addition, there was a decrease in urinary glycosaminoglycan excretion after only one week of treatment ${ }^{21}$. In a nonrandomized study, Krassas et al. ${ }^{11}$ observed favorable responses to octreotide ( $0.1 \mathrm{mg}$ three times daily for 3 months) in 7 of 12 patients $(58 \%)$ with active ophthalmopathy. These beneficial effects were achieved in patients who had positive octreoscans prior to treatment ${ }^{11}$. In a similar uncontrolled study (octreotide, $0.1 \mathrm{mg}$ three times daily for 8 weeks) Khoo et al. ${ }^{22}$ reported an improvement of eye disease in 6 of 8 patients $(75 \%)$. Comparison between the effects of either octreotide $(0.2 \mathrm{mg}$ three times daily for 3 months) or prednisone was made by Kung et al. ${ }^{23}$ who observed, in an open randomized study, that octreotide treatment was associated with an improvement in ocular conditions in 5 of 8 patients $(62 \%$; 1 complete response and 4 partial responses); however, in this study the effectiveness of octreotide was not as high as that of prednisone. Ozata et al. ${ }^{24}$ observed a clinical response (most evident on soft tissue involvement) in 5 of 10 patients $(50 \%)$ treated with the above doses of octreotide: this was associated with a decrease in serum intercellular adhesion molecule-1 (ICAM-1) levels, suggesting a reduced endothelial and fibroblast activation. Another nonrandomized study reported positive results with octreotide therapy in 7 of 9 patients $(78 \%)^{25}$. A major limitation of octreotide is its short half-life, which requires multiple daily injections. To overcome this problem, the use of the long-acting analogue, lanreotide, was proposed. Krassas et al. ${ }^{16}$ found that lanreotide ( $40 \mathrm{mg}$ every other week for 3 months) was effective in all 5 patients (100\%); a subsequent nonrandomized study from the same group ${ }^{26}$ showed a favorable outcome in all 10 patients with no differences between the subgroups treated with octreotide or lanreotide. Finally, in a recent report by Krassas et al. ${ }^{27}$, mainly devoted to the study of serum cytokine and adhesion molecule concentrations during SMSa therapy. Responders to treatment were 9 of 15 enrolled patients $(60 \%)$.

In summary, the available data indicate favorable effects of SMSa in slightly more than $70 \%$ of patients (Table 3). Side effects of this treatment are very limited. These promising results must, however, be weighed against the following considerations: i) The number of patients so far treated is too small (Table 3); ii) Most published studies are nonrandomized or uncontrolled; iii) A selection bias was probably applied in some stud- 
Table 3. Overall effects of somatostatin analogue (SMSa) on Graves' ophthalmopathy.

\begin{tabular}{|c|c|c|c|c|c|}
\hline \multirow[t]{2}{*}{ Author } & \multirow[t]{2}{*}{ Year } & \multirow[t]{2}{*}{ SMSa } & \multirow{2}{*}{$\begin{array}{l}\text { Patients } \\
\text { (n) }\end{array}$} & \multicolumn{2}{|c|}{ Responders } \\
\hline & & & & (n) & $(\%)$ \\
\hline Chang & 1992 & Octreotide & 6 & 6 & 100 \\
\hline Krassas & 1995 & Octreotide & 11 & 7 & 58 \\
\hline Khoo & 1995 & Octreotide & 8 & 6 & 75 \\
\hline Kung & 1996 & Octreotide & 8 & 5 & 62 \\
\hline Ozata & 1996 & Octreotide & 10 & 5 & 50 \\
\hline Uysal & 1999 & Octreotide & 9 & 7 & 78 \\
\hline Krassas & 1999 & Octreotide & 5 & 5 & 100 \\
\hline Krassas & 2001 & Octreotide & 6 & 3 & 50 \\
\hline Krassas & 1997 & Lanreotide & 5 & 5 & 100 \\
\hline Krassas & 1999 & Lanreotide & 5 & 5 & 100 \\
\hline Krassas & 2001 & Lanreotide & 9 & 6 & 67 \\
\hline Total & & & 82 & 60 & 76 \\
\hline
\end{tabular}

ies! because positivity of pretherapy octreoscans was a prerequisite for enrollment of patients. Should the activity of the ophthalmopathy have been considered a prerequisite to enroll patients in previous studies, overall results of high-dose glucocorticoid treatment or orbital radiotherapy would probably be much better than those reported in the literature (see 1 for review). Accordingly, large, multicenter, prospective and randomized studies are needed to draw definite conclusions on SMsa effectiveness. In addition, comparison with established methods of treatment for GO (namely, high-dose glucocorticoids or orbital radiotherapy) should also be made to assess, in comparable series of patients, the relative effectiveness and tolerability of the different treatments. Finally, the high cost of these drugs must be taken into account before including them among the established treatments for GO.

\section{INTRAVENOUS IMMUNOGLOBULINS}

Human iv immunoglobulins (IvIg) have been used with a variable degree of success in several inflammatory/autoimmune disorders, such as thrombocytopenic purpura, membranous glomerulonephritis, myasthenia gravis, polymyositis, Guillain-Barre syndrome, vasculitis and Kawasaki's disease ${ }^{28}$. Recently, IvIg have also been used in systemic lupus erythematosus, with favorable, although frequently transient, responses in $75-85 \%$ of $\operatorname{cases}^{29}$. Their mechanism of action is not fully understood but immunoglobulins might act by blocking idiotypic epitopes through anti-idiotypic antibodies, by down-regulating immunocompetent cells through suppression of Fcg receptors, by modulating or suppressing cytokine secretion or by solubilizing immune complexes ${ }^{1}$. Whether all the above targets are relevant for GO remains to be unequivocally demonstrated.

The first nonrandomized study on the use of IvIg for GO was published 10 years ago by Antonelli et al. ${ }^{30}$ who treated 7 patients with high-dose IvIg alone $(400 \mathrm{mg} / \mathrm{kg}$ / day for 5 consecutive days; the cycle was repeated five times at 3-week intervals) and 7 patients with IvIg associated with orbital radiotherapy; the results were compared with a so-called "historical" group of patients previously treated with high-dose glucocorticoids and orbital radiotherapy. They found that IvIg, either alone or combined with orbital radiotherapy, caused an improvement in the ocular conditions which did not substantially differ from that observed with the "historical" group ${ }^{30}$. The same authors subsequently reported the results of another prospective, nonrandomized study in which the percentage of responders to $\operatorname{IvIg}(76 \%)$ was similar to the percentage of responders to systemic glucocorticoids $^{31}$. In the only randomized study, Kahaly et al. ${ }^{32}$ reported a similar percentage of successful outcome (slightly more than $60 \%$ ) in patients treated with either systemic glucocorticoids or IvIg. On the other hand, Seppel et al. ${ }^{33}$ failed to show any beneficial effect of this treatment in $10 \mathrm{GO}$ patients.

This treatment has not gained wide popularity among thyroidologists and no further reports on its use for GO have been published in the last 5 years. As a matter of fact, in a recent survey of the European Thyroid Association only $2 \%$ of respondents suggested its use for this disease $^{6}$. The reasons for this reluctancy can be summarized as follows: i) Results so far published refer to small 
series of patients and all studies but one are nonrandomized; ii) Treatment is very expensive; iii) There is concern as to the possibility of disease transmission using plasma-derived products. For example, an outbreak of hepatitis $\mathrm{C}$ was associated with IvIg treatment in the United States in the period October 1993-June 1994 $4^{34}$.

Bearing these important limitations in mind, we do not believe that, in spite of enthusiastic reports, available data presently justify the choice of IvIg, at least as a first-line therapeutic approach, for GO. Carefully conducted, prospective, randomized and controlled studies of large series of patients are required to support or disprove our current attitude.

\section{IMMUNOSUPPRESSIVE DRUGS}

The use of immunosuppressive drugs other than steroids was proposed on the basis of the autoimmune nature of $\mathrm{GO}^{1}$. However, results obtained with several immunosuppressants or immunomodulators, like azathioprine, cyclophosphamide, chlorambucil and ciamexone, have generally been discouraging ${ }^{35}$. Results with cyclosporine as a single agent were rather conflicting but mostly nonsatisfactory ${ }^{1}$. However, even though poorly effective as a single agent, cyclosporine might have a role, according to Prummel et al. ${ }^{36}$, in association with glucocorticoids, in patients who do not respond to glucocorticoids alone. While its use in transplanted patients or in severe autoimmune disorders is obviously worthwhile (and may be inevitable), the potential toxicity of cyclosporine must seriously be taken into account before using it for a disease such as GO. Thus, GO management with immunosuppressive agents other than glucocorticoids is not very popular. As a matter of fact, cyclosporine or azathioprine were indicated as a suitable therapeutic option by only $6 \%$ and $2 \%$ of respondents, respectively, to the recent European Thyroid Association survey ${ }^{6}$.

Another immunosuppressive agent which is currently being evaluated in GO patients is methotrexate. This drug, together with its metabolites, inhibits several enzymes in the folic acid metabolic pathway ${ }^{37}$. When used at high doses, it has cytotoxic and antiproliferative actions attributed to the inhibition of dihydrofolate reductase activity leading to inhibition of DNA, RNA and protein synthesis ${ }^{37}$. Chronic, low-dose treatment with methotrexate causes an accumulation of adenosine, a lymphotoxic and anti-inflammatory autocoid ${ }^{38}$. Methotrexate also affects cytokine synthesis and secretion since it increases interleukin (IL)-2 production and decreases sol- uble IL-2 receptor, IL-6, IL-8 and leucotriene B4 production $^{38}$. In addition, methotrexate impairs neutrophil chemotaxis $^{38}$. Low-dose methotrexate is useful for the management of nonneoplastic disorders, such as rheumatoid arthritis ${ }^{39}$, psoriasis ${ }^{40}$, sarcoidosis $^{41}$, asthma ${ }^{42}$ and Crohn's disease ${ }^{38}$. Particularly interesting in all the above conditions is the glucocorticoid-sparing effect of methotrexate since in several series, patients were weaned from or required lower doses of glucocorticoids following the addition of methotrexate.

Thus, methotrexate is by no means a novel drug. However, it has not systematically been evaluated in GO management. Indeed, the only available report on the use of methotrexate for this disease is a study of its role in noninfectious orbital inflammatory disorders: among the 14 patients reported, three were affected with $\mathrm{GO}^{43}$. All three patients, treated with a maximum of $20-25 \mathrm{mg} /$ day for long periods of time (25-36 months), had an improvement in their ocular conditions, with particular effect on soft tissue changes, extraocular muscle involvement and, in one case, visual acuity ${ }^{43}$. In addition to this report, Heufelder communicated preliminary (and as yet unpublished in a final form) favorable results in a few patients treated with methotrexate for refractory ophthalmopathy ${ }^{44}$. Thus, data must be considered anecdotical. Nevertheless, methotrexate, the use of which was indicated by $1 \%$ of respondents to the European Thyroid Association survey ${ }^{6}$, probably deserves a more careful evaluation in controlled and randomized prospective studies. We are rather skeptical about its true effectiveness and the possibility that treatment outcomes may substantially differ from those reported with other immunosuppressive drugs. Our current view, based on what was reported in other disorders, such as rheumatoid arthritis, asthma and sarcoidosis, is that methotrexate should not be used as a first-line treatment, but might, at low doses, have a role as a second-line therapeutic approach, in association with disease-modifying treatments in patients with persistently active and recalcitrant ophthalmopathy, with the aim of reducing the dose of glucocorticoids necessary to control the clinical picture. As for other medical treatments, methotrexate should probably be used early in the course of the ophthalmopathy when the disease is florid and active. Finally, when proposing methotrexate as a therapeutic tool for GO, its possible side effects, albeit usually reversible and responsive to dose reductions, should carefully be considered in a cost/benefit assessment. The latter include gastrointestinal disturbances, an increased risk of opportunistic infections, bone marrow depression, interstitial pneumonitis and liver toxicity ${ }^{42}$. Conception and pregnancy 
should be avoided for at least 6 months after drug withdrawal because of its teratogenic effect ${ }^{42}$. Folate represents a useful antidote to methotrexate toxicity, without affecting its effectiveness.

Whether tacrolimus, an immunosuppressive drug inhibiting immunophilins, might be beneficial for $\mathrm{GO}$ as it proved to be for other autoimmune disorders ${ }^{45,46}$, is conjectural.

\section{ANTIOXIDANTS}

Thyroid hormones increase the mitochondrial respiration, causing a hypermetabolic state associated with an increased generation of oxygen free radicals: such a metabolic oxidation and a reduced antioxidant capacity may contribute to signs and symptoms of hyperthyroidism ${ }^{47}$. Oxidation also represents an important mechanism in thyroid hormone synthesis, through oxidation of iodide and coupling of iodotyrosines to form iodothyronines $^{48}$. Tissue damage in hyperthyroidism might be related to the increased oxygen free radical genera$\operatorname{tion}^{48,49}$. In a human study, the use of an antioxidant mixture (vitamin E, vitamin C, b-carotene, copper, zinc and manganese) in association with methimazole induced a more rapid decrease in serum thyroid hormone levels and a prompter amelioration of clinical signs and symptoms of thyrotoxicosis than methimazole alone ${ }^{50}$.

As far as GO is concerned, oxygen free radicals have been shown in vitro to stimulate proliferation of orbital fibroblasts ${ }^{51-53}$ and their expression of $72-\mathrm{kDa}$ heat shock protein $^{52}$. In vitro antioxidant agents, nicotinamide and allopurinol, block superoxide-induced proliferation of orbital fibroblasts ${ }^{53}$; in addition, nicotinamide inhibits cytokine-induced expression of both major histocompatibility antigen class II antigens and SICAM-1 from the same cells ${ }^{54}$. Further to these studies, an in vivo study was carried out in GO patients on the effects of the antioxidant agents, allopurinol (300 mg daily) and nicotinamide (300 mg daily), given for three months ${ }^{55}$. In this prospective, nonrandomized, comparative study, two groups of 11 patients with mild-to-moderately severe ophthalmopathy were given either antioxidants or placebo: improvement of ocular conditions occurred in 9 of $11(82 \%)$ antioxidant-treated patients, but only in 3 of $11(27 \%)$ placebo-treated patients $(\mathrm{p}<0.05)^{55}$ (Figure 3). Pain (either spontaneous or with eye movements) improved in all patients, diplopia ameliorated in 4 of 7 (57\%), proptosis was little affected by treatment; 10 of 11 patients reported satisfaction with treatment outcome in the self-assessment evaluation ${ }^{55}$.

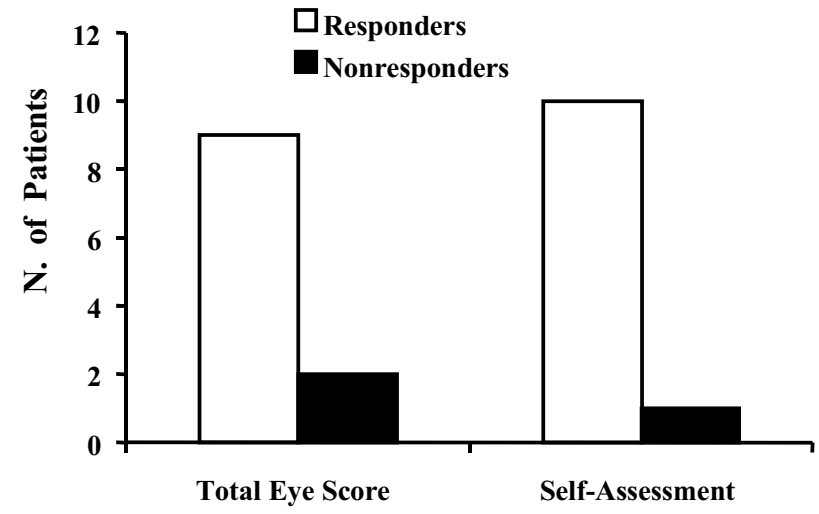

Figure 3. Effects of antioxidants (allopurinol and nicotinamide) on Graves' ophthalmopathy. Responses were evaluated in terms of reduction of the Total Eye Score and of patient's satisfaction at selfassessment evaluation. Derived from Bouzas EA et al. ${ }^{55}$.

Because this interesting study is the only one available on the use of antioxidants for GO, it is premature to draw conclusions on their effectiveness and results must be interpreted with caution. Larger, prospective randomized studies are warranted to address this issue. However, the rationale for antioxidant utilization is rather sound, based on in vitro studies, and the side effects of these drugs are very limited. Therefore, in the future the use of antioxidants for GO might be envisioned, at least in light-to-moderate eye disease and as co-adjuvants for more powerful established treatments, like high-dose glucocorticoids.

\section{CYTOKINE ANTAGONISTS}

Cytokines play an important role in GO pathogenesis, although they probably are more important for perpetuating the disease than for triggering $\mathrm{it}^{56}$. Cytokines exert actions that are relevant for eye disease, such as induction of expression of major histocompatibility class II molecules, heat-shock protein-72 and sICAM- ${ }^{57}$. In addition, they stimulate orbital fibroblasts to proliferate ${ }^{58}$ and to secrete glycosaminoglycans ${ }^{59}$.T-cells in the orbital tissue of GO patients have either a Th-1 profile of cytokine production (cell-mediated immunity: IL-2, interferon (IFN- $\gamma$, tumor necrosis factor (TNF- $\alpha)^{60}$ or a Th-2 pattern (humoral immunity: IL-4, IL-5, IL-10) ${ }^{61,62}$, possibly depending upon the stage of the ophthalmopathy (Th1 in an early stage, Th-2 late in the course of the disease). Based on the above observations, it is evident that blockade of the cascade of events involving cytokines might play an important role in GO management, particularly in the early stage of the disease. 
Cytokine blockade can be achieved by different means, i.e., by cytokine receptor antagonists, monoclonal antibodies to cytokines, soluble cytokine receptors, or counterregulatory cytokines ${ }^{63,64}$. Trials with cytokine antagonists have been carried out or are ongoing in some pathophysiological conditions. For example, in the management of rheumatoid arthritis, monoclonal antibodies to human TNF- $\alpha^{65-67}$ and soluble IL-1 receptor ${ }^{68}$ have been used with variable degree of success ${ }^{69}$. Likewise, clinical trials are ongoing on anti-TNF- $\alpha$ therapies for Crohn's disease, sepsis and myelodisplastic syndromes ${ }^{70}$.

As far as GO is concerned, available information is rather limited ${ }^{1}$. A few years ago Tan et al. showed that both soluble IL-1 receptor antagonist (sIL-1RA), which binds to IL-1 receptor but does not activate it, and sIL$1 \mathrm{R}$ produced a dose-dependent inhibition of IL-1-induced glycosaminoglycan production in cultured orbital fibroblasts from $\mathrm{GO}^{71}$. IL-1RA was also shown to counteract IL-1 effects on human thyrocytes in culture ${ }^{72}$. Thus, at least in vitro, IL-1 antagonists could inhibit the action of IL-1, a proinflammatory cytokine believed to play a pivotal role in the orbital tissue of patients with ophthalmopathy ${ }^{73}$. Interestingly, the expression of IL-1RA in orbital fibroblasts from both Graves' patients and controls could be inhibited by low-dose UV irradiation, but not by dexamethasone ${ }^{74}$ : these findings, while unraveling a new mechanism of action of orbital radiotherapy for $\mathrm{GO}$, underscore the concept that glucocorticoids act not only to counteract proinflammatory cytokines, but also to balance agonist and antagonist mediators, thus preventing hyperactivity of the immune system. In a human study, Hofbauer et al. ${ }^{75}$ reported that GO patients who responded to orbital radiotherapy had significantly higher baseline sIL-1RA levels and a greater sIL-1RA increase during treatment than patients who did not respond. The value of measuring baseline sIL-1RA levels was not confirmed by Salvi et al. ${ }^{76}$ who found similar levels in patients with ophthalmopathy and controls. In addition, baseline sIL-1RA concentration was not predictive of the subsequent response or lack of response to high-dose glucocorticoids ${ }^{77}$.

So far, the only available data on the effects of cytokine antagonists in vivo on GO were reported by Balazs et al. using pentoxifylline ${ }^{78}$. This drug, an analogue of methylxanthine theobromine widely used for peripheral vascular disorders, has complex immunomodulatory effects on cytokine production ${ }^{79}$. Pentoxifylline inhibits proliferation and glycosaminoglycan synthesis of cultured orbital fibroblasts derived from GO patients ${ }^{80}$. In addition, this drug blocks glycosaminoglycan production and
HLA-DR expression induced by IL-1, TNF- $\alpha$ and IFN- $\gamma$ in orbital fibroblasts ${ }^{81}$. Pentoxifylline interferes with the second messenger pathways of a variety of cytokines, including TNF- $\alpha$, IL-1 $\beta$ and transforming growth factor$\beta^{70}$. Based on this premise Balazs et al. ${ }^{78}$, in a nonrandomized and uncontrolled study, treated 10 patients with moderately severe GO with pentoxifylline (200 mg daily iv for 10 days, followed by $1800 \mathrm{mg} /$ daily orally for 4 weeks, then reduced to $1200 \mathrm{mg}$ daily until the end of a 3 -month treatment). Eight patients (80\%) responded favorably in terms of an overall evaluation carried out by assesing variations of the Total Eye Score (Figure 4$)^{78}$. Soft tissue changes and proptosis were most responsive, whereas extraocular muscle involvement response was less impressive ${ }^{78}$. Clearly, the results of this preliminary study must be interpreted with caution and randomized and controlled studies are, also in this case, required to assess more accurately the true effectiveness of pentoxifylline. No other study on the use of IL-1 or TNF- $\alpha$ antagonists is available for GO. Such studies are clearly difficult to perform for several reasons: i) Given the complex network of cytokines, it is difficult to ascertain which cytokine(s) should be blocked; ii) It will not be easy to determine the drug dose (administered systemically) that will reach and be effective on orbital tissue; iii) Longterm safety and cost/benefit evaluations are warranted. Topical soluble TNF- $\alpha$ receptor type I suppresses cytokine gene expression and allogeneic corneal transplant in rats ${ }^{82}$. Whether a similar protocol of locally administered cytokine antagonists might in the future be applied to GO is entirely speculative.

\section{TOTAL THYROID ABLATION}

GO is a disorder of autoimmune origin, but its pathogenic mechanisms are not fully understood ${ }^{1}$. A popular

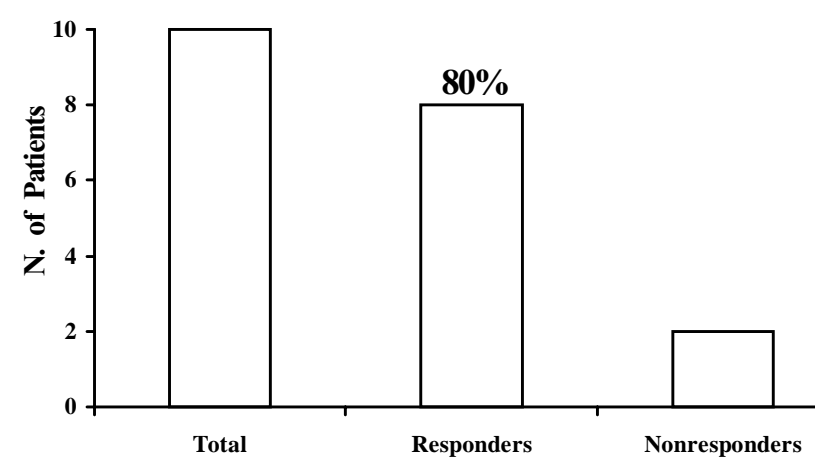

Figure 4. Effects of pentoxifylline on Graves' ophthalmopathy. Derived from Balazs $\mathrm{C}$ et al. $^{78}$. 
hypothesis links eye disease to the thyroid through the "shared" antigen(s) theory ${ }^{83}$. According to it, the initial event would be represented by the presence of autoreactive T-lymphocytes capable of recognizing and interacting with one or more antigens shared by the thyroid and the orbital tissue ${ }^{83}$. Autoreactive T-lymphocytes would then be recruited in the orbit by systemic and locally produced adhesion molecules and heat-shock proteins; after antigen recognition, a cascade of events would be primed to fibroblast proliferation, preadipocyte-fibroblast differentiation into adipocytes, secretion of glycosaminoglycans and secretion of a complex array of cytokines (responsible for maintenance of the ongoing processes $)^{1}$. The nature of the antigen(s) shared by the thyroid and the orbit is still elusive, but the TSH-receptor is a good candidate ${ }^{84}$. Likewise, the type of orbital cell primarily involved in the reaction is presently undefined but fibroblasts and adipocytes are more likely the culprit than myocytes ${ }^{84}$.

If this pathogenic hypothesis is correct, the presence of thyroid tissue bearing the bulk of shared antigen(s) may represent an unfavorable starting point for the development or progression of the ophthalmopathy in subjects who bear the appropriate genetic background and are exposed to environmental risk factors, such as cigarette smoking. While environmental risk factors have been, at least in part, defined, genetic factors remain to be fully elucidated, although they probably play a less relevant role compared to environmental factors ${ }^{85,86}$.

The concept that total thyroid ablation reduces thyroid autoimmune phenomena is supported by the observation that total thyroidectomy followed by radioiodine therapy is associated with a progressive decrease and disappearance of circulating autoantibodies in initially antibody-positive thyroid cancer patients who are diseasefree after treatment ${ }^{87}$. Therefore, also in the case of GO, total antigen deprivation and autoreactive T-lymphocyte depletion might prove beneficial for eye disease ${ }^{88}$. On the other hand, if orbital autoantigens are not crossreactive with the thyroid, removal of thyroid autoantigens (and autoreactive T lymphocytes) would not affect the autoimmune processes involved in the ophthalmopathy ${ }^{89}$. Furthermore, in well established and longstanding ophthalmopathy, autoimmune reactions ongoing in the orbit might have become independent of the presence or absence of residual thyroid tissue. Thyroid ablation has in the past been considered as a tool to also treat associated ophthalmopathy. However, literature data, derived from nonrandomized studies, are controversial: after initial positive reports ${ }^{90,91}$ other clinical trials failed to show any relevant influence of this approach for the ophthalmopathy ${ }^{92}$. Indirect evidence for a link between total thyroid ablation and improvement of eye disease comes from a study showing that the risk of GO progression is higher in patients who require more than one dose of radioiodine than in those who become hypothyroid after the first therapeutic dose ${ }^{93}$. Recent nonrandomized and uncontrolled studies on this issue were performed by DeG$\operatorname{root}^{94,95}$. In one study, 15 patients with severe GO were evaluated; they were in most cases hypothyroid under replacement therapy after treatment for hyperthyroidism; residual thyroid tissue was demonstrated, in spite of the hypothyroid state, by a persisting thyroidal radioiodine uptake $>1 \%{ }^{95}$. When these patients were further treated by radioiodine therapy, 11 of them $(73 \%)$ showed an amelioration of ocular parameters, whereas the remaining 4 patients were considered as nonresponders ${ }^{95}$ (Figure 5). Of course, these results must be interpreted with caution, since DeGroot's studies were neither randomized nor controlled. However, they must prompt the performance of clinical trials addressing this issue, like the prospective, randomized and controlled study presently ongoing in our Institutions.

\section{PREVENTION}

GO prevention might theoretically be carried out at different stages. Eye disease schematically goes through three different stages. Stage 1 is the absence of disease, stage 2 is represented by the absence of clinical disease (but the presence of subclinical ocular involvement), stage 3 is when clinical disease (either active or inactive) is present (Table 4). Progression from stage 1 to stage 2 and from stage 2 to stage 3 does not occur in all patients since about $40-45 \%$ of Graves' patients apparently have

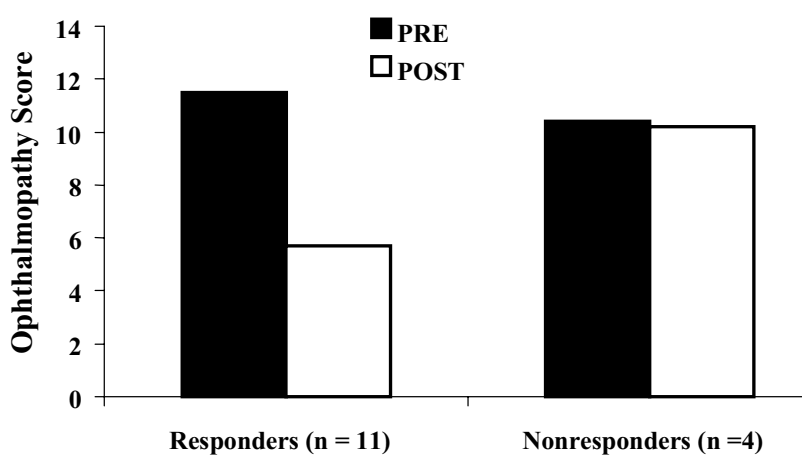

Figure 5. Effects of total thyroid ablation on Graves' ophthalmopathy. Illustrated in the figure are mean changes in the ophthalmopathy score in responders and nonresponders to total thyroid ablation. Derived from DeGroot LJ and Benjasuratwong $\mathrm{Y}^{95}$. 
no ocular involvement, about $50 \%$ have sublinical (or mild) ophthalmopathy, and only 3-5\% have severe eye disease requiring specific and aggressive treatments ${ }^{1}$. The reason why only a minority of patients develop severe GO is unknown. This disease derives from a complex and not fully understood interplay of endogenous (genetic) and exogenous (environmental) factors ${ }^{85,86}$. At present, preventive intervention can only be carried out on exogenous risk factors. The latter include cigarette smoking ${ }^{96}$, thyroid dysfunction, both hyper- $-{ }^{97,98}$ and hypothyroidism ${ }^{99}$ and radioiodine therapy for hyperthyroidism ${ }^{100-102}$.

Cigarette smoking is widely used by patients with the ophthalmopathy ${ }^{103}$ and is associated with more severe disease ${ }^{104,105}$. Furthermore, smoking reduces the effectiveness of orbital radiotherapy and high-dose glucocorticoids $^{106}$. Interestingly, smoking withdrawal seems to be associated with a decreased risk of occurrence of clinical disease ${ }^{107}$. Accordingly, patients with Graves' disease should be urged to refrain from smoking because this measure may be helpful in preventing the occurrence of subclinical disease (primary prevention), the progression to clinical disease (secondary prevention) and the exacerbation of overt disease (tertiary prevention) ${ }^{85,86}$.

Correction of hyperthyroidism or treatment-induced hypothyroidism is also very important for the ophthalmopathy. Restoration of euthyroidism is associated with an amelioration of eye disease ${ }^{97}$. In addition, GO may occur or worsen often after a variable period of hypothyroidism ${ }^{99}$. Thus, a careful control of thyroid function seems essential, at least in terms of secondary and tertiary prevention ${ }^{7,86}$. Whether this should be achieved by thyroid ablation ${ }^{88}$ or by a prolonged antithyroid drug treatment ${ }^{108}$ remains a matter of controversy.

Radioiodine therapy effects on the ophthalmopathy are controversial, but results of the few randomized studies so far available ${ }^{103-105}$ lend support to the concept that this treatment bears a limited but defined risk of causing progression of eye disease, particularly in patients who have associated risk factors, such as preexisting ophthalmopathy, severe hyperthyroidism, high TSH levels, high TSH-receptor antibody levels and cigarette smoking ${ }^{1}$
(Table 4). This should not lead to avoidance of radioiodine therapy for Graves' hyperthyroidism because the possible exacerbation of the ophthalmopathy can be prevented by simultaneous administration of middle-dose glucocorticoids ${ }^{100,102}$. Thus, the latter therapeutic measure represents a useful tool, at least in terms of secondary and tertiary GO prevention ${ }^{86}$.

It is recommended that earlier diagnosis (and treatment) of hyperthyroidism, as well as earlier diagnosis (and treatment) of the ophthalmopathy, be achieved, but, again, these measures are mostly directed to secondary and tertiary prevention of the disease.

Can we do something in terms of primary prevention? At the present status of understanding of GO pathogenic mechanisms and immunogenetic basis, the answer is no. However, novel approaches might be on the horizon. Oral tolerization might represent a future possible preventive approach. Immune tolerance can be induced by the oral (or nasal) administration of the offending antigen. This procedure was successfully applied to experimental animal autoimmune disorders: soluble oral type II collagen suppresses or reduces the severity of type II collagen-induced arthritis in mice ${ }^{109}$; oral porcine insulin administration suppresses diabetes in nonobese diabetic (NOD) mice ${ }^{110}$; oral administration of myelin basic protein suppresses experimental autoimmune encephalomyelitis ${ }^{111}$; orally administered acetylcholine receptor suppresses experimental autoimmune myasthenia ${ }^{112}$. Oral tolerization has been attempted in human disorders: oral type II chicken collagen was reported to improve chronic rheumatoid arthritis ${ }^{113}$; orally given myelin basic protein decreased recurrences in patients with multiple sclerosis ${ }^{114}$. It should be noted that these encouraging but preliminary results still await confirmation in larger and randomized studies. Oral administration of human thyroglobulin produces immune tolerance in thyroglobulininduced experimental autoimmune thyroiditis in mice, with suppression of humoral and cell-mediated immune responses and of thyroid pathologic changes ${ }^{115}$; however, oral administration of human thyroglobulin does not influence the incidence of spontaneous and iodine-induced lymphocytic thyroiditis in the BB/Wor rats ${ }^{116}$. Thy-

Table 4. Staging of Graves' ophthalmopathy.

\begin{tabular}{|c|c|c|c|}
\hline Stage & Definition & Aim of prevention & Methods \\
\hline I & Absence of disease & Avoidance of GO occurrence & Immmunologic intervention(?); stop smoking \\
\hline II & Subclinical disease & Avoidance of progression to overt disease & $\begin{array}{l}\text { Early diagnosis and treatment of hyperthyroidism } \\
\text { and GO; stop smoking; steroid coverage after }{ }^{131} \text {-therapy }\end{array}$ \\
\hline III & Clinical disease & Avoidance of deterioration and complications & Treatment of GO; stop smoking; total thyroid ablation (?) \\
\hline
\end{tabular}


Table 5. Risk factors for progression of the ophthalmopathy after radioiodine therapy for Graves' hyperthyroidism.

Preexisting ophthalmopathy

Cigarette smoking

Severe pretherapy hyperthyroidism

Uncorrected postradioiodine hypothyroidism

High TSH-receptor antibody levels

roglobulin of thyroid origin has recently been found in the orbital tissue of GO patients ${ }^{117}$. Should thyroglobulin be one of the antigens involved in the pathogenesis of the ophthalmopathy, oral tolerance induction might prove beneficial for the prevention of eye disease. Oral administration of desiccated porcine thyroid preparations to patients with autoimmune thyroid disorders, while not affecting humoral immunity, was associated with slight changes in cell-mediated reactions to TSH-receptor peptides and thyroid peroxidase ${ }^{118}$. Thus, available data are not unequivocal and need to be further confirmed. However, vaccination with the antigen(s) responsible for the cross-reaction and the orbit (e.g., TSH-receptor peptides, the transgenically expressed extracellular domain of the TSH-receptor, thyroglobulin or other antigens possibly intervening in the mechanism of disease) might produce useful preventive effects in patients who are genetically susceptible to the disease (Table 6). Another possible immune intervention might be represented by the use of specific antigen-presenting dendritic cells (loaded, for

Table 6. Future interventions for Graves' ophthalmopathy.

\section{Cytokine antagonists}

Sound rationale from in vitro studies; use in vivo in other autoimmune disorders (e.g., rheumatoid arthritis); only one preliminary study of the effect of pentoxyfilline on GO

\section{Antioxidants}

Sound rationale from in vitro studies; only one pilot study of the effects of allopurinol and nicotinamide on GO

\section{Immunologic intervention}

Oral tolerization or vaccination with offending antigen(s); preliminary results in other autoimmune disorders

\section{Immunosuppressive drugs}

Evaluation of methotrexate: possible use as a second-line drug allowing a glucocorticoid-sparing effect

\section{Total thyroid ablation}

Aimed at removal of autoreactive intrathyroidal T-lymphocytes and shared antigen(s) crossreacting with thyroid and orbit; only few nonrandomized and uncontrolled studies available; possibly useful in the early stage of eye disease example, with TSH-receptor peptides) which do not stimulate Th1 cells but cause a condition of tolerance/anergy. These immunologic interventions imply that we can identify subjects who in the future will develop Graves' disease and ophthalmopathy. This is not possible at the moment. Accordingly, these putative novel approaches are presently theoretical because the mechanism of disease and the antigen(s) primarily involved, as well as the genetic background conferring susceptibility to GO, remain to be fully clarified.

\section{CONCLUDING REMARKS}

GO represents a complex therapeutic challenge. The outcome of available treatments is often disappointing, and at the end of follow-up many patients are dissatisfied with the results obtained ${ }^{3}$. Once the disease is established, it is difficult to obtain its complete regression. Accordingly, novel treatments capable of intervening on the mechanisms of disease before GO develops or early in its course will be welcome (Table 6). Although the progress in our understanding of GO pathogenesis has been more impressive than that in its management, either novel treatments (SMSa) or novel modalities of established treatments (iv glucocorticoids) have provided encouraging results for overt eye disease. In the field of immunosuppressive drugs, a possible role of low-dose methotrexate is currently being evaluated (at least in mild-to-moderate ophthalmopathy) and the very preliminary results are promising. The possible role of antioxidants deserves to be evaluated. Early intervention in both GO and associated hyperthyroidism is a necessary prerequisite to improve whatever treatment outcome. The most promising novel therapeutic approach is probably represented by cytokine antagonists: these drugs might, indeed, interrupt the vicious cycle of reactions that occur in the orbit, are mediated by cytokine secretion and lead to perpetuation of eye disease. They have been used in other autoimmune disorders (particularly rheumatoid arthritis) with encouraging results: they might also work on GO. The only available report on cytokine antagonists for GO refers to the use of pentoxifylline in a pilot study. Further to the hypothesis that GO may occur in the context of autoimmune reactions to antigen(s) shared by the thyroid and the orbit, total thyroid ablation might be useful to arrest progression of the ophthalmopathy. GO prevention would be desirable rather than treatment of established disease. Presently our possibilities are limited to secondary and tertiary prevention, but in the (near?) future oral tolerance or vaccination with the autoantigen(s) responsible for triggering eye disease 
might be feasible and allow primary prevention of the disease.

\section{ACKNOWLEDGEMENTS}

This work was supported in part by grants from the University of Insubria, Varese, Italy (Fondi d'Ateneo per la Ricerca) to Luigi Bartalena.

\section{REFERENCES}

1. Bartalena L, Pinchera A, Marcocci C 2000 Management of Graves' ophthalmopathy: reality and perspectives. Endocr Rev 21: 168-99.

2. Gerding MN, Terwee CB, Dekker FW, Koornneef L, Prummel MF, Wiersinga WM 1997 Quality of life in patients with Graves' ophthalmopathy is markedly decreased: measurements by the Medical Outcomes Study Instrument. Thyroid 7: 885-9.

3. Bartley GB, Fatourechi V, Kardmas EF, Jacobsen SJ, Ilstrup DM, Garrity JA, Gorman CA 1996 Long-term follow-up of Graves' ophthalmopathy in an incidence cohort. Ophthalmology 103: 958-62.

4. Bartalena L, Marcocci C, Pinchera A 2002 Management of thyroid eye disease. Eur J Nucl Med, in press.

5. Krassas GE, Heufelder AE 2001 Immunosuppressive therapy in patients with thyroid eye disease: an overview of current concepts. Eur J Endocrinol 144: 311-8.

6. Weetman AP, Wiersinga WM 1998 Current management of thyroid-associated ophthalmopathy in Europe. Results of an international survey. Clin Endocrinol (Oxf) 49: 21-8.

7. Bartalena L, Marcocci C, Bogazzi F, Bruno-Bossio G, Pinchera A 1991 Glucocorticoid therapy of Graves' ophthalmopathy. Exp Clin Endocrinol 97: 320-7.

8. Marcocci C, Bartalena L, Tanda ML, Manetti L, Dell' Unto E, Rocchi R, Barbesino G, Mazzi B, Bartolomei MP, Lepri P, Cartei F, Nardi M, Pinchera A 2001 Comparison of the effectiveness and tolerability of intravenous or oral glucocorticoids associated with orbital radiotherapy in the management of severe Graves' ophthalmopathy: results of a prospective, single-blind, randomized study. J Clin Endocrinol Metab 86: 3562-7.

9. Weissel M, Hauff W 2000 Fatal liver failure after highdose glucocorticoid pulse therapy in a patient with severe thyroid eye disease. Thyroid 10: 521 (Letter).

10. Postema PTE, Krenning EP, Wijngaarde R, Kooy PPM, Oei HY, van den Bosch WA, Reubi JC, Wiersinga WM, Hooijkaas Hour, van der Loos T, Poublon RML, Lamberts SWJ, Hennemann G 1994 ( ${ }^{111}$ In-DTPA-D-Phe1) octreotide scintigraphy in thyroidal and orbital Graves' disease: a parameter for disease activity? J Clin Endocrinol Metab 79: 1845-51.

11. Krassas GE, Dumas A, Pontikides N, Kaltsas T 1995 Somatostatin receptor scintigraphy and octreotide treatment in patients with thyroid eye disease. Clin Endocrinol (Oxf) 42: $571-80$

12. Kahaly G, Diaz M, Hahn K, Beyer J, Bockish A 1995 In- dium-111-pentetreotide scintigraphy in Graves' ophthalmopathy. J Nucl Med 36: 550-4.

13. Moncayo R, Baldissera I, De Cristoforo C, Kendler D, Donnemiller E 1997 Evaluation of immunological mechanisms mediating thyroid-associated ophthalmopathy by radionuclide imaging using the somatostatin analog ${ }^{111} \mathrm{In}$ octreotide. Thyroid 7: 21-9.

14. Kahaly G, Diaz M, Just M, Beyer J, Lieb W 1995 Role of octreoscan and correlation with MR imaging in Graves' ophthalmopathy. Thyroid 5: 107-11.

15. Wiersinga WM, Gerding MN, Prummel MF, Krenning EP 1998 Octreotide scintigraphy in thyroidal and orbital Graves' disease. Thyroid 8: 433-6.

16. Krassas GE, Kaltsas T, Dumas A, Pontikides N, Tolis G 1997 Lanreotide in the treatment of patients with thyroid eye disease. Eur J Endocrinol 136: 416-22.

17. Kahaly G, Rainer G, Diaz M, Hommel G, Bockisch A 1998 Indium-111-pentetreotide in Graves' disease. J Nucl Med 39: 533-6.

18. Colao A, Lastoria S, Ferone D, Pivonello R, Macchia PE,Vassallo P, Bonavolonta G, Muto P, Lombardi G, Fenzi GF 1998 Orbital scintigraphy with ( ${ }^{111}$ In-diethylenetriamine pentaacetic acid-D-Phe1)-octreotide predicts the clinical response to corticosteroid therapy in patients with Graves' ophthalmopathy. J Clin Endocrinol Metab 83: 3790-4.

19. Krassas GE, Kahaly G 1999 The role of octreoscan in thyroid eye disease. Eur J Endocrinol 140: 373-5.

20. Chang TC, Kao SCS, Huang KM 1992 Octreotide and Graves' ophthalmopathy and pretibial myxoedema. $\mathrm{Br}$ Med J 304: 158.

21. Chang TC, Yao WC, Chang CC 1992 Octreotide and urinary glycosaminoglycan in Graves' disease. Br Med J 304: 1444 (Letter).

22. Khoo DHC, Tan YT, Fok ACK, Tan CE 1995 Octreotide in the management of Graves' ophthalmopathy- Changes in insulin-like growth factor 1 levels do not predict clinical response. Am J Clin Res 4: 33-42.

23. Kung AWC, Michon J, Tai KS, Chan FL 1996 The effect of somatostatin versus corticosteroid in the treatment of Graves' ophthalmopathy. Thyroid 6: 381-4.

24. Ozata M, Bolu E, Sengul A, Tasar M, Beyhan Z, Corakci A, Gundogan MA 1996 Effect of octreotide treatment on Graves' ophthalmopathy and circulating sICAM-1 levels. Thyroid 6: 283-8.

25. Uysal AR, Corapcioglu D, Tonyukuk VC, Gullu S, Sav Hour, Kamel N, Erdogan G 1999 Effect of octreotide treatment on Graves' ophthalmopathy. Endocr J 46: 573-7.

26. Krassas GE, Doumas A, Kaltsas T, Halkias A, Pontikides N 1999 Somatostatin receptor scintigraphy before and after treatment with somatostatin analogues in patients with thyroid eye disease. Thyroid 9: 47-52.

27. Krassas GE, Pontikides N, Doukidis D, Heufelder G, Heufelder AE 2001 Serum levels of tumor necrosis factor- $\alpha$, soluble intercellular adhesion molecule- 1 , soluble vascular cell adhesion molecule-1, and soluble interleukin1 receptor antagonist in patients with thyroid eye disease undergoing treatment with somatostatin analogues. Thy- 
roid 11: 1115-22.

28. Ratko TA, Burnett DA, Foulke GE and the University Hospital Consortium Expert Panel for Off-Label Use of Polyvalent Intravenously administered Immunoglobulin Preparations 1995 Recommendations for off-label use of intravenously administered immunoglobulin preparations. JAMA 273: 1865-70.

29. Ruiz-Irastorza G, Khamashta MA, Hughes GRV 2000 Therapy of systemic lupus erythematosus: new agents and new evidence. Exp Opin Invest Drugs 9: 1-13.

30. Antonelli A, Saracino A, Alberti B, Canapicchi R, Cartei F, Lepri A, Laddaga M, Baschieri L 1992 High-dose intravenous immunoglobulin treatment in Graves' ophthalmopathy. Acta Endocrinol (Copenh) 126: 13-23.

31. Baschieri L, Antonelli A, Nardi S, Alberti B, Lepri A, Canapicchi R, Fallahi P 1997 Intravenous immunoglobulin versus corticosteroid in treatment of Graves' ophthalmopathy. Thyroid 7: 579-85.

32. Kahaly G, Pitz S, Muller-Forell W, Hommel G 1996 Randomized trial of intravenous immunoglobulins versus prednisolone in Graves' ophthalmopathy. Clin Exp Immunol 106: 197-202.

33. Seppel T, Schlaghecke R, Becker A, Engelbrecht V, Feldkamp J, Kornely E 1996 High-dose intravenous therapy with 7S immunoglobulins in autoimmune endocrine ophthalmopathy. Clin Exp Immunol 14 (Suppl 15): S109-S114.

34. Anonymous 1994 Outbreak of hepatitis C associated with intravenous immunoglobulin administration - United States, October 1993-June 1994. MMWR 43: 505-9.

35. Bartalena L, Marcocci C, Pinchera A 1997 Treating severe Graves' ophthalmopathy. Bailliere's Clin Endocrinol Metab 11: 521-36.

36. Prummel MF, Mourits MP, Berghout A, Krenning EP, van der Gaag R, Koornneef L, Wiersinga WM 1989 Prednisone and cyclosporine in the treatment of severe Graves' ophthalmopathy. N Engl J Med 321: 1353-9.

37. Seitz M 1999 Molecular and cellular effects of methotrexate. Curr Opin Rheumatol 11: 226-32.

38. Rampton DS 2001 Methotrexate in Crohn's disease. Gut 48: 790-1.

39. Weinblatt ME, Coblyn JS, Fox DA 1985 Efficacy of lowdose methotrexate in rheumatoid arthritis. N Engl J Med 312: 818-22.

40. Wilkens RF, Williams HJ, Ward JR 1984 Randomized, double-blind, placebo controlled trial of low-dose pulse methotrexate in psoriatic arthritis. Arthritis Rheum 27: 376-81.

41. Baughman RP, Lower EE 1999 A clinical approach to the use of methotrexate for sarcoidosis. Thorax 54: 742-6.

42. Mullarkey MF 1997 Methotrexate revisited. Chest 112: 1-2.

43. Smith JR, Rosenbaum JT 2001 A role of methotrexate in the management of non-infectious orbital inflammatory disease. Br J Ophthalmol 85: 1220-4.

44. Heufelder AE 2000 Thyroid-associated ophthalmopathy: current dilemmas and future challenges. Proc of the Meeting "Progress in thyroid associated ophthalmopathy", Kyoto, October 21, 2000, p. 46-8.
45. Ishioka M, Ohno S, Nakamura S, Isobe K, Watanabe N, Ishigatsubo Y,Tanaka S 1994 FK506 treatment of noninfectious uveitis. Am J Ophthalmol 118: 723-9.

46. Duddridge M, Powell RJ 1997 Treatment of severe and difficult cases of systemic lupus erythematosus with tacrolimus. A report of three cases. Ann Rheum Dis 56: 690-2.

47. Venditti P, Balestrieri M, Di Meo S, De Leo T 1997 Effect of thyroid state on lipid peroxidation, antioxidant defences, and susceptibility to oxidative stress in rat tissues. J Endocrinol 155: 151-7.

48. Doerge DR, Taurog A, Dorris M 1994 Evidence for a radical mechanism in peroxidase-catalyzed coupling. I. Steady-state experiments with various peroxidases. Arch Biochem Biophys 315: 82-9.

49. Mano T, Shinohara R, Sawai Y, Oda N, Nishida T, Mokuno T, Kotake M, Hamada M, Masunaga R, Nakai A, Nagasaka A 1995 Effects of thyroid hormone on coenzyme $\mathrm{Q}$ and other free radical scavengers in rat heart muscle. $\mathrm{J}$ Endocrinol 145: 131-6.

50. Guerra LN, Moiguer S, Karner M, Rios de Molina MC, Sreider CM, Burdman JA 2001 Antioxidants in the treatment of Graves' disease. IUBMB Life 51: 105-9.

51. Murrel GA, Francis MJ, Bromley L 1990 Modulation of fibroblast proliferation by oxygen free radicals. Biochem J 265: 659-65.

52. Heufelder AE, Wenzel BE, Bahn RS 1992 Methimazole and propylthiouracil inhibit the oxygen free radical-induced expression of a 72 kilodalton heat shock protein in Graves' retroocular fibroblasts. J Clin Endocrinol Metab 74: 737-42.

53. Burch HB, Lahiri S, Bahn RS, Barnes S 1997 Superoxide radical production stimulates retroocular fibroblast proliferation in Graves' ophthalmopathy. Exp Eye Res 65: 311-6.

54. Hiromatsu Y, Yang D, Miyake I, Koga M, Kameo J, Sato M, Inoue Y, Nonaka K 1998 Nicotinamide decreases cytokine-induced activation of orbital fibroblasts from patients with thyroid-associated ophthalmopathy. J Clin Endocrinol Metab 83: 121-4.

55. Bouzas EA, Karadimas P, Mastorakos G, Koutras DA 2000 Antioxidant agents in the treatment of Graves' ophthalmopathy. Am J Ophthalmol 129: 618-22.

56. Wiersinga WM, Prummel MF 2001 Pathogenesis of Graves' ophthalmopathy-Current understanding. J Clin Endocrinol Metab 86: 501-3.

57. Bahn RS 1996 Graves' ophthalmopathy: the role of cytokines in pathogenesis. In Gass GH and Kaplan HM (eds.), Handbook of Endocrinology, 2nd Ed., vol 1, CRC Press, Boca Raton, p. 287-95.

58. Heufelder AE, Bahn RS 1994 Modulation of Graves' orbital fibroblast proliferation by cytokines and glucocorticoid receptor agonists. Invest Vis Sci 35: 120-7.

59. Smith TJ, Bahn RS, Gorman CA, Cheavens M 1991 Stimulation of glycosaminoglycan accumulation by interferon $\mathrm{g}$ in cultured retroocular fibroblasts. J Clin Endocrinol Metab 72: 1169-71.

60. De Carli MM, Mariotti S, Marcocci C, Pinchera A, Ricci M, Romagnani S, Del Prete G 1993 Cytolytic T cells with 
Th1-like cytokine profile predominate in retroorbital lymphocytic infiltrates of Graves' ophthalmopathy. J Clin Endocrinol Metab 77: 1120-4.

61. Grubeck-Loebenstein B, Trieb K, Sztankay A, Holter W, Anderl H, Wick G 1994 Retrobulbar T cells from patients with Graves' ophthalmopathy are CD8+ and specifically recognize autologous fibroblasts. J Clin Invest 5: 273843.

62. MacLachlan SM, Prummel M, Rapoport B 1994 Cellmediated or humoral immunity in Graves' ophthalmopathy? Profiles of T-cell cytokines amplified by polymerase chain reaction from orbital tissue. J Clin Endocrinol Metab 78: 1070-4.

63. Dobets R, Savelkoul HFJ 1994 Cytokine antagonists and their potential therapeutic use. Immunol Today 15: 455-8.

64. Bartalena L, Marcocci C, Pinchera A 1996 Cytokine antagonists: new ideas for the management of Graves' ophthalmopathy. J Clin Endocrinol Metab 81: 446-8.

65. Elliott MJ, Maini RN, Feldmann M, Long-Fox A, Charles P, Bijl H, Woody JN 1994 Repeated therapy with monoclonal antibody to tumour necrosis factor $\alpha$ (CA2) in patients with rheumatoid arthritis. Lancet 344: 1125-7.

66. Elliott MJ, Maini RN, Feldmann M, Kalden JR, Antoni C, Smolen JS, Leeb B, Breedveld FC, Macfarlane JD, Bijl H, Woody JN 1994 Randomised double-blind comparison of chimeric monoclonal antibody to tumour necrosis factor $\alpha$ (CA2) versus placebo in rheumatoid arthritis. Lancet 344: 1105-10.

67. Rankin ECC, Choy EHS, Kassimos D, Kingsley GH, Sopwith AM, Isenberg DA, Panayi GS 1995 The therapeutic effects of an engineered human anti-tumour necrosis factor alpha antibody (CDP571) in rheumatoir arthritis. $\mathrm{Br}$ J Rheumatol 34: 344-52.

68. Drevlow BE, Lovis R, Haag MA, Sinacore JN, Jacobs C, Blosche C, Landay A, Moreland LW, Pope RM 1996 Recombinant human interleukin-1 receptor type $\mathrm{I}$ in the treatment of patients with active rheumatoid arthritis. Arthr Rheum 39: 257-65.

69. McQueen FM 1997 The use of biologics in the treatment of rheumatoid arthritis - the good news and the bad news. Aust NZ J Med 27: 175-84.

70. Raza A 2000 Anti-TNF therapies in rheumatoid arthritis, Crohn's disease, sepsis, and myelodisplastic syndromes. Micr Res Techn 50: 229-35.

71. Tan GH, Dutton CM, Bahn RS 1996 Interleukin-1 (IL-1) receptor antagonist and soluble IL-1 receptor inhibit IL1-induced glycosaminoglycan production in cultured human orbital fibroblasts from patients with Graves' ophthalmopathy. J Clin Endocrinol Metab 81: 449-52.

72. Krogh Rasmussen A, Diamant M, Blichert-Toft M, Bendtzen K, Feldt-Rasmussen U 1997 The effects of interleukin-1 $\beta$ (IL-1 $\beta$ ) on human thyrocyte functions are counteracted by the IL-1 receptor antagonist. Endocrinology 138: 2043-8.

73. Bahn RS 2000 Understanding the immunology of Graves' ophthalmopathy. Is it an autoimmune disease? Endocrinol Metab Clin N Am 29: 287-96.

74. Muhlberg T, Joba W, Spitzweg C, Schworm H-D, Heber- ling H-J, Heufelder AE 2000 Interleukin-1 receptor antagonist ribonucleic acid and protein expression by cultured Graves' and normal orbital fibroblasts is differentially modulated by dexamethasone and irradiation. J Clin Endocrinol Metab 85: 734-42.

75. Hofbauer LC, Muhlberg T, Konig A, Heufelder G, Schworm H-D, Heufelder AE 1997 Soluble interleukin-1 receptor antagonist serum levels in smokers and nonsmokers with Graves' ophthalmopathy undergoing orbital radiotherapy. J Clin Endocrinol Metab 82: 2244-7.

76. Salvi M, Pedrazzoni M, Girasole G, Giuliani N, Minelli R, Wall JR, Roti E 2000 Serum concentrations of proinflammatory cytokines in Graves' disease: effect of thyroid function, ophthalmopathy and cigarette smoking. Eur J Endocrinol 143: 197-202.

77. Bartalena L, Manetti L, Tanda ML, Dell'Unto E, Mazzi B, Rocchi R, Barbesino G, Pinchera A, Marcocci C 2000 Soluble interleukin-1 receptor antagonist concentration is neither related to cigarette smoking nor predictive of subsequent response to glucocorticoids. Clin Endocrinol (Oxf) 52: 647-51.

78. Balazs C, Kiss E, Vamos A, Molnar I, Farid NR 1997 Beneficial effect of pentoxifylline on thyroid associated ophthalmopathy (TAO): a pilot study. J Clin Endocrinol Metab 82: 1999-2002.

79. Balazs C, Kiss E, Farid NR 1997 Inhibitory effect of pentoxifylline on HLA-DR expression and glycosaminoglycan synthesis of retrobulbar fibroblasts induced by interferon gamma. Acta Microbiol Immunol Hung 44: 173-9.

80. Chang C-C, Chang T-C, Kao SCS, Kuo Y-F, Chien L-F 1993 Pentoxifylline inhibits the proliferation and glycosaminoglycan synthesis of cultured fibroblasts derived from patients with Graves' ophthalmopathy and pretibial myxoedema. Acta Endocrinol (Copenh) 129: 322-7.

81. Balazs C, Kiss H, Farid NR 1998 Inhibitory effect of pentoxifylline on HLA-DR expression and glycosaminoglycan synthesis by retrobulbar fibroblasts. Horm Metab Res 30: 496-9.

82. Qian Y, Dekaris I, Yamagami S, Dana R 2000 Topical soluble tumor necrosis factor receptor type I suppresses ocular chemokine gene expression and rejection of allogeneic corneal transplants. Arch Ophthalmol 118: 166671.

83. Burch HB, Wartofsky L 1993 Graves' ophthalmopathy: current concepts regarding pathogenesis and management. Endocr Rev 14: 747-93.

84. McGregor AM 1998 Has the target autoantigen for Graves' ophthalmopathy been found? Lancet 352: 595-6.

85. Bartalena L, Marcocci C, Pinchera A 2002 Graves' ophthalmopathy: a preventable disease? Eur J Endocrinol 146: 000-000.

86. Wiersinga WM, Bartalena L 2002 Epidemiology and prevention of Graves' ophthalmopathy. Thyroid, in press

87. Pacini F, Mariotti S, Formica N, Elisei R, Anelli S, Capotorti E, Pinchera A 1988 Thyroid autoantibodies in thyroid cancer: incidence and relation with tumour outcome. Acta Endocrinol (Copenh) 119: 373-80.

88. Marcocci C, Bartalena L, Pinchera A 1998 Ablative or 
non-ablative therapy for Graves' hyperthyroidism in patients with ophthalmopathy? J Endocrinol Invest 21: 46871.

89. Weetman AP, Harrison BJ 1998 Ablative or non-ablative therapy for Graves' hyperthyroidism in patients with ophthalmopathy? J Endocrinol Invest 21: 472-5.

90. Bauer FK, Catz B 1966 Radioactive iodine therapy for progressive malignant exophthalmos. Acta Endocrinol (Copenh) 51: 15-22.

91. Werner SC, Feind CR, Aida M 1967 Graves' disease and total thyroidectomy. Progression of severe eye changes and decrease in serum long-acting thyroid stimulation after operation. N Engl J Med 276: 132-8.

92. Volpe R, Desbarais-Schonbaum M-L, Schonbaum E, Row V, Ezrin C. 1969 The effect of radioablation of the thyroid gland in Graves' disease with high levels of long-acting thyroid stimulator (LATS). Am J Med 46: 217-26.

93. DeGroot LJ, Mangklabruks A, McCormick M 1990 Comparison of RA131I treatment protocols for Graves' disease. J Endocrinol Invest 13: 111-8.

94. DeGroot LJ 1997 Radioiodine and the immune system. Thyroid 7: 259-64

95. DeGroot LJ, Benjasuratwong Y 1996 Evaluation of thyroid ablative therapy for ophthalmopathy of Graves' disease. Orbit 15: 187-96.

96. Bartalena L, Bogazzi F, Tanda ML, Manetti L, Dell’Unto E, Martino E 1995 Cigarette smoking and the thyroid. Eur J Endocrinol 133: 507-12.

97. Prummel MF, Wiersinga WM, Mourits MP, Koornneef L, Berghout A, van der Gaag R 1989 Amelioration of eye changes of Graves' ophthalmopathy by achieving euthyroidism. Acta Endocrinol (Copenh) 121 (Suppl 2): 185-9.

98. Prummel MF, Wiersinga WM, Mourits MP, Koornneef L, Berghout A, van der Gaag R 1990 Effect of abnormal thyroid function on the severity of Graves' ophthalmopathy. Arch Intern Med 150: 1098-101.

99. Karlsson AF, Westermark K, Dahlberg PA, Jansson R, Enoksson P 1989 Ophthalmopathy and thyroid stimulation. Lancet 2: 691 (Letter).

100. Bartalena L, Marcocci C, Bogazzi F, Panicucci M, Lepri A, Pinchera A 1989 Use of corticosteroids to prevent progression of Graves' ophthalmopathy after radioiodine therapy for hyperthyroidism. N Engl J Med 321: 1349-52.

101. Tallstedt L, Lundell G, Torring O, Wallin G, Ljunggren J-G, Blomgren A, Taube A and the Thyroid Study Group 1992 Occurrence of ophthalmopathy after treatment for Graves' hyperthyroidism. N Engl J Med 326: 1733-8.

102. Bartalena L, Marcocci C, Manetti L, Tanda ML, Dell'Unto E, Bruno-Bossio G, Nardi M, Bartolomei, Lepri A, Rossi G, Martino E, Pinchera A 1998 Relation between therapy for hyperthyroidism and the course of Graves' ophthalmopathy. N Engl J Med 338: 73-8.

103. Bartalena L, Martino E, Marcocci C, Bogazzi M, Panicucci M, Velluzzi F, Loviselli A, Pinchera A 1989 More on smoking habits and Graves' ophthalmopathy. J Endo- crinol Invest 12: 733-7.

104. Vestergaard P 2002 Smoking and thyroid disorders - a meta-analysis. Eur J Endocrinol 146: 153-61.

105. Prummel MF, Wiersinga WM 1993 Smoking and risk of Graves' disease. JAMA 269: 469-72.

106. Bartalena L, Marcocci C, Tanda ML, Manetti L, Dell'Unto E, Bartolomei MP, Nardi M, Martino E, Pinchera A 1998 Cigarette smoking and treatment outcomes in Graves' ophthalmopathy. Ann Intern Med 129: 632-5.

107. Pfeilschifter J, Ziegler R 1996 Smoking and endocrine ophthalmopathy: impact of smoking severity and current vs. lifetime cigarette consumption. Clin Endocrinol (Oxf) 45: 477-81.

108. Wiersinga WM 1998 Preventing Graves' ophthalmopathy. N Engl J Med 338: 121-2.

109. Nagler-Anderson C, Bober LA, Roberson ME, Siskind GW, Thorbecke GL 1986 Suppression of type II collageninduced arthritis by intragastric administration of soluble type II collagen. Proc Natl Acad Sci USA 83: 7443-6.

110. Zangh ZJ, Davidson L, Eisenbarth G, Weiner HL 1991 Suppression of diabetes in NOD mice by oral administration of porcine insulin. Proc Natl Acad Sci USA 88: 10252-6.

111. Bitar D, Whitacre CC 1988 Suppression of experimental autoimmune encephalomyelitis by the oral administration of myelin basic protein. Cell Immunol 112: 364-70.

112. Wang Z-Y, Qiao J, Link H 1993 Suppression of experimental autoimmune myasthenia gravis by oral administration of acethylcholine receptor. J Neuroimmunol 44: 299-314.

113. Trentham DE, Dynesius-Trentham R, Orav EJ, Khoury SJ, Dawson DM, Hafler D, Weiner HL. 1993 Effect of oral administration of type II collagen on rheumatoid arthritis. Science 261: 1727-30.

114. Weiner HL, Mackin GA, Matsui M, Orav EJ, Khoury SJ, Dawson DM, Hafler DA 1993 Double-blind pilot trial of oral tolerization with myelin antigens in multiple sclerosis. Science 259: 1321-4.

115. Guimaraes VC, Quintans J, Fisfalen M-E, Straus FH, Wilhelm K, Madeiros-Neto GA, DeGroot LJ 1995 Suppression of development of experimental autoimmune thyroiditis by oral administration of thyroglobulin. Endocrinology 136: 3353-9.

116. Colzani RM, Alex S, Dunn AD, Stone S, Braverman LE 1999 The oral administration of human thyroglobulin does not affect the incidence of lymphocytic thyroiditis in the biobreeding Worcester rat. Thyroid 9: 831-5.

117. Marinò M, Lisi S, Pinchera A, Mazzi B, Latrofa F, Sellari-Franceschini S, McCluskey RT, Chiovato L 2001 Identification of thyroglobulin in orbital tissues of patients with thyroid-associated ophthalmopathy. Thyroid 11: 177-85.

118. Lee S, Scherberg N, DeGroot LJ 1998 Induction of oral tolerance in human autoimmune thyroid disease. Thyroid 8: 229-34. 